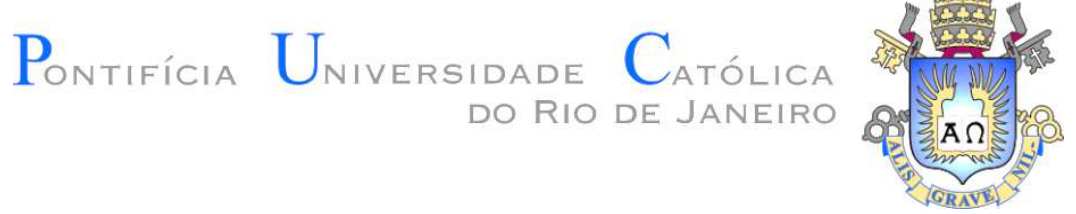

Larissa de Aguiar Barbosa Soares

Obras de Arte Paisagísticas à Luz
da Filosofia de Heidegger

Dissertação de Mestrado

Dissertação apresentada como requisito parcial para obtenção do grau de Mestre pelo Programa de Pós-Graduação em Filosofia do Departamento de Filosofia da PUC-Rio.

Orientador: Prof. Luis Camillo Osório Co-orientadora: Profa. Ligia Saramago 
Larissa de Aguiar Barbosa Soares

\section{Obras de Arte Paisagísticas à Luz da Filosofia de Heidegger}

\section{Dissertação de Mestrado}

Dissertação para apresentação como requisito parcial para obtenção do grau de Mestre pelo Programa de Pós-graduação em Filosofia da PUCRio do Departamento de Filosofia da PUC-Rio. Aprovada pela Comissão Examinadora abaixo assinada.

Prof. Luiz Camillo Dollabella Portella Osório de Almeida

Orientador

Departamento de Filosofia - PUC-Rio

Profa Ligia Teresa Saramago Pádua

Co-orientadora

Departamento de Filosofia -- PUC-Rio

Prof. Gilvan Luiz Fogel

Departamento de filosofia do IFCS - UFRJ

Prof. Edgar de Brito Lyra Neto Departamento de Filosofia -- PUC-Rio

Profa Denise Berruezo Portinari Coordenadora Setorial do Centro de Teologia

E Ciências Humanas - PUC-Rio 
Todos os direitos reservados. É proibida a reprodução total ou parcial do trabalho sem a autorização da universidade, da autora e do orientador.

\section{Larissa de Aguiar Barbosa Soares}

Graduou-se em Arquitetura e Urbanismo na Pontifícia Universidade Católica do Rio de Janeiro. Participante da VII Bienal Internacional de Arquitetura de São Paulo. Trabalhou junto com o paisagista Eduardo Barra e o arquiteto Hermano Freitas. Integrante da comissão organizadora das XI e XII Semana dos Alunos da Pós-Graduação em Filosofia da PUC-Rio e da IV Jornada Heidegger.

Ficha Catalográfica

Soares, Larissa de Aguiar Barbosa

Obras de arte paisagísticas à luz da filosofia de Heidegger / Larissa de Aguiar Barbosa Soares ; orientador: Luis Camillo Osório. - 2012. 170 f. il. (color.) ; $30 \mathrm{~cm}$

Dissertação (mestrado)-Pontifícia Universidade Católica do Rio de Janeiro, Departamento de Filosofia, 2012.

Inclui bibliografia

1. Filosofia - Teses. 2. Heidegger. 3. Paisagem. 4. Arte. 5. Espaço. 6. Roberto Burle Marx. 7. Robert Smithson. I. Osório, Luis Camillo. II. Pontifícia Universidade Católica do Rio de Janeiro. Departamento de Filosofia. III. Título. 
Àquele que está sempre amorosamente ao meu lado, meu querido marido. 


\section{Agradecimentos}

Ao CNPq e à PUC-Rio, pelo auxílio concedido, sem o qual esta pesquisa não seria possível.

Ao meu orientador Luiz Camillo Osório e à minha co-orientadora Ligia Saramago que me guiaram pacientemente no caminho do pensamento filosófico.

Aos funcionários do departamento de filosofia, Edna, Dinah e Leonardo, que sempre me atenderam com simpatia e presteza, assim como a nossa gentil coordenadora Vera Bueno.

Aos professores Edgar Lyra e Eduardo Jardim que acompanharam o desenvolvimento desta pesquisa e contribuíram com comentários edificantes.

Ao professor Gilvan Fogel por me inspirar uma leitura poética de Heidegger.

Aos meus amigos e colegas do departamento de filosofia, em especial à Maria Priscilla Coelho, que sempre me contagia com seu amor pela filosofia e por sua imensa energia.

A minha querida amiga Isadora Maleval, que tanto me ajudou na revisão técnica da dissertação.

Aos meus amigos Hermano Freitas e Eduardo Barra por terem contribuído enormemente na minha formação como arquiteta, me ensinando a amar a arquitetura e a arquitetura paisagística.

Agradeço postumamente a Norberg Schultz por ter se dedicado a aproximar o pensamento heideggeriano à arquitetura, mesmo que indiretamente, me convidando a fazer o mesmo.

Aos meus sogros, Vera e Carlos, que muito me apoiaram, de inúmeras maneiras, através de grandes e pequenos gestos. Obrigada por estarem sempre atentos e presentes. 
Aos meus pais, Leoniza e Ilques, pela dedicação e incentivo sem medida à minha formação acadêmica. Agradeço sinceramente por terem me ensinado a superar minhas dificuldades e não me acanhar frente àqueles sonhos "aparentemente" impossíveis.

Ao meu marido, Daniel Soares, para quem qualquer agradecimento sempre será pequeno. Seu amor é a mão segura que me guia nas veredas da vida. 


\section{Resumo}

Soares, Larissa de Aguiar Barbosa; de Almeida, Luiz Camillo Dollabella Portella. Pádua, Ligia Tereza Saramago. Obras de Arte Paisagísticas à Luz da Filosofia de Heidegger. Rio de Janeiro, 2012. 170 p. Dissertação de Mestrado - Departamento de Filosofia, Pontifícia Universidade Católica do Rio de Janeiro.

A pesquisa se volta à filosofia de Martin Heidegger para iluminar obras de arte contemporâneas que dizem respeito à paisagem. Embora Heidegger não tenha abordado diretamente este tema, aparecem inúmeras referências à paisagem ao longo de sua obra, seja por meio de metáforas ou desenvolvimento de tópicos correlatos. Para isso, enfocou-se, especialmente, seus escritos sobre natureza, arte, espaço e o habitar poético. Objetivou-se explorar três questões: a relação entre natureza, arte e paisagem; a elaboração artística da paisagem como uma construção conjunta entre artista e natureza; e, por fim, a construção de uma nova compreensão espacial da paisagem a partir da obra de arte. Assim sendo, por meio de duas obras paradigmáticas: o Parque do Flamengo (1965), de Roberto Burle Marx e a Spiral Jetty (1970), de Robert Smithson, discutiremos, respectivamente, as duas últimas questões colocadas anteriormente.

\section{Palavras chave}

Heidegger; paisagem; arte; espaço; Roberto Burle Marx; Robert Smithson. 


\section{Abstract}

Soares, Larissa de Aguiar Barbosa. de Almeida, Luiz Camillo Dollabella Portella (Advisor). Pádua, Ligia Tereza Saramago (Co-advisor) Landscape Works of Art in the light of Heidegger's Philosophy. Rio de Janeiro, 2012. 170 p. MSc. Dissertation - Departamento de Filosofia, Pontifícia Universidade Católica do Rio de Janeiro.

The research turns to Martin Heidegger's philosophy to illuminate contemporary works of art that relate to the landscape. Although Heidegger has not directly addressed this issue, numerous references to the landscape appears through his work, whether in metaphors or co-related topics. Therefore, we focused especially his writings on nature, art, space and dwelling. This study aimed to explore three issues: the relationship between nature, art and landscape, the construction of a work of art joint between artist and nature, and finally, the construction of a new understanding of the landscape space from the work art. Thus, from two paradigmatic works - Park of Flamengo (1965), Roberto Burle Marx, and the Spiral Jetty (1970), Robert Smithson - will be discussed, respectively, the last two questions.

\section{Keywords}

Heidegger; landscape; art; space; Roberto Burle Marx; Robert Smithson. 


\section{Sumário}

1. Introdução 14

2. Como compreender paisagem em heidegger? 17

2.1. A paisagem esquecida na circunvisão da ação 18

2.2. A contemplação da paisagem como uma possibilidade da ocupação mundana 25

2.3. A stimmung da paisagem 30

2.4. A paisagem como sinal 39

2.5. O encontro autêntico com a paisagem: a paisagem como um acontecimento 43

3. A arte e a paisagem 54

3.1. A arte e a obra de arte em heidegger 54

3.2. Paisagem: a relação entre arte e natureza 76

3.3. Obras de arte paisagísticas à luz da filosofia de heidegger 87

4. A paisagem obra 91

4.1. A paisagem como obra de arte - o parque do flamengo 97

4.2. A construção poética da obra paisagística 99

4.3. A obra paisagística como um processo continuamente

4.4. A obra de arte e os guardiões da obra 116

5. A obra paisagem 125

5.1. Robert smithson: novas possibilidades espaciais para a

paisagem 127

5.2. Non-site: o container da paisagem obra 134

5.3. A obra paisagem, o non-site, sob uma perspectiva heideggeriana 140

5.4. A spiral jetty e a abertura de espaços em heidegger 148

6. Considerações finais 158

7. Referências bibliográficas 165 


\section{Lista de Abreviaturas}

OBRAS UTILIZADAS

ST - Ser e Tempo

EC - Ensaios e Conferências

PPP - Porque Permanecemos na Província?

HHT - Heidegger's Hut

HBC - Heidegger in Benjamin's City

$\mathrm{HH}$ - Hinos de Hölderlin

OOA - A Origem da Obra de Arte

MV - Modernidade Verde: Jardins de Burle Marx

AP - Arte e Paisagem: Conferências Escolhidas

FRB - Flores Raras e Banalíssimas

DPUE - Dos Parques, Un Equipo

AAN - A Arte da Natureza

RSCW - Robert Smithson: the Collected Writings 


\section{Lista de figuras}

Figura 1 - Pintura. Lavoura de trigo com ceifador. 63

Figura 2 - Pintura. Lavoura de trigo, ceifador e

sol nascendo.

Figura 3 - Pintura. Paisagem com montes de

feno e lua nascendo.

Figura 4 - Pintura. Paisagem com Enéas em Delos. 82

Figura 5 - Foto. Jardim Stounhead.

Figura 6 - Desenho. Caderno vermelho

de Humphry Repton.

Figura 7 - Foto. Annual Rings. 86

Figura 8 - Foto. Monumentos de Neguev. 86

Figura 9 - Foto. Boundary Split. $\quad 86$

Figura 10 - Sítio St. Antônio da Bica. 86

Figura 11 - Double Negative. 86

Figura 12 - Cocheiras. $\quad 86$

Figura 13 - Desenho. Parque do Flamengo. 89

Figura 14 - Desenho. Spiral Jetty. $\quad 89$

Figura 15 - Grass Grows. $\quad 94$

Figura 16 - Desenho. Deslocamento de terra. 95

Figura 17 - Foto. Construção do Aterro do Flamengo 1.

Figura 18 - Foto. Construção do Aterro do Flamengo 2.

Figura 19 - Foto. Construção do Aterro do Flamengo 3.

Figura 20 - Foto. Construção do Aterro do Flamengo 4.

Figura 21 - Montagem. Praia do Flamengo antes. 104

Figura 22 - Montagem. Praia do Flamengo antes. 104

Figura 23 - Foto. Vista aérea 1. 106

Figura 24 - Foto. Vista aérea 2. 106 
Figura 25 - Foto. Monumento dos pracinhas.

Figura 26 - Foto. Museu de Arte Moderna.

Figura 27 - Foto. Passarela para o Museu de

Arte Moderna. p. 107.

Figura 28 - Foto. Coreto no Parque do Flamengo. 107

Figura 29 - Foto. Caminho no Parque do Flamengo. 120

Figura 30 - Foto. Palmeiras. 120

Figura 31 - Foto. Moradores informais. 120

Figura 32 - Foto. Flambayonts. 120

Figura 33 - Foto. Figueiras. 120

Figura 34 - Foto. Ciclovia. 121

Figura 35 - Foto. Carnaval. 121

Figura 36 - Foto. Skatista. $\quad 121$

Figura 37 - Foto. Áreas sombreadas. 121

Figura 38 - Foto. Ficus microcarpa. 121

Figura 39 - Foto. Palmeiras Corifas. 121

Figura 40 - Foto. Robert Smitshon. 130

Figura 41 - Foto. Spiral Jetty. $\quad 130$

Figura 42 - Foto. Spiral Jetty quase submersa. 131

Figura 43 - Foto. Spiral Jetty emersa. 131

Figura 44 - Foto. Spiral Jetty completamente seca. 131

Figura 45 - Foto. Incrustação de sal. 133

Figura 46 - Foto. Lago vermelho. 133

Figura 47 - Foto. Exibição do Filme Spiral Jetty. 135

Figura 48 - Desenho. Story-board do filme. 135

Figura 49 - Cenas do filme Spiral Jetty 1.

Figura 50 - Cenas do filme Spiral Jetty 2.

Figura 51 - Desenho. Espirais. 136 
O caminho recolhe aquilo que tem seu ser em torno dele; e dá a cada um dos que o percorre aquilo que é seu. Os mesmos campos, as mesmas ondulações da colina escoltam o caminho em cada estação, em sua vizinhança com proximidade sempre nova. Quer a cordilheira dos Alpes acima das florestas se dissolva no crepúsculo da tarde, quer - onde o caminho ondula entre os outeiros - a cotovia se lance ao céu na manhã de verão, quer o vento leste sopre a tempestade desde a região da aldeia natal da mãe, quer o lenhador carregue, ao cair da noite, seu feixe de lenha para a lareira, quer o carro da colheita se arraste em direção ao celeiro, oscilando pelos sulcos do caminho, quer colham as crianças as primeiras flores da primavera na borda do prado, quer passeie a neblina ao longo do dia melancolicamente sua massa sobre o vale, sempre e de todos os lados fala, em torno do caminho do campo, o apelo do Mesmo.

Heidegger, O caminho do campo 